\title{
CRÉDITOS LABORALES Y TRABAJADORES EN EL PROCEDIMIENTO DE REORGANIZACIÓN JUDICIAL, LEY N ${ }^{\circ} 20.720$ (ANÁLISIS CRÍTICO DESDE UNA VISIÓN COMPARADA)
}

\author{
WORKERS AND LABOR CREDITS IN THE PROCEDURE OF JUDICIAL \\ REORGANIZATION, LAW N 20.720 (CRITICAL ANALYSIS FROM A \\ COMPARED VISION)
}

\section{EdUARDo JEQUier LEHUEDÉ ${ }^{*}$}

\begin{abstract}
RESUMEN: La ley concursal, $\mathrm{N}^{\circ}$ 20.720, regula la reorganización de la empresa deudora insolvente aunque económicamente viable, mediante la reestructuración de sus activos y pasivos. Notamos aquí una importante omisión en lo que concierne a la regulación de la situación jurídica de los trabajadores de la empresa y del tratamiento de los créditos laborales. Este trabajo aborda los efectos jurídicos y prácticos que genera tal omisión, desde una perspectiva comparada.
\end{abstract}

Palabras clave: Reorganización, Ley N²0.720, créditos laborales.

ABSTRACT: The Bankruptcy act, $N^{\circ}$ 20.720, deals with the reorganization of insolvent though economically viable companies, by means of the restructuring of its assets and liabilities. We notice here an important omission regarding the regulation of the legal situation of the workers of the company and of the treatment of the labor credits. This work approaches the legal and practical effects that such an omission generates, from a compared perspective.

Key words: Reorganization, Law $N^{\circ} 20.720$, labor credits.

\section{INTRODUCCIÓN}

La Ley $N^{\circ} 20.720$-en adelante ley concursal o LC- carece de una regulación que defina con claridad la situación en que se encuentran los créditos laborales y los trabajadores de una empresa deudora sometida a reorganización. La única referencia que hace la LC a cuestiones laborales en este procedimiento se contiene en el art. $57 \mathrm{~N}^{\circ} 1$, a propósito de la denominada "protección financiera concursal", que conecta tangencialmente con la situación de los trabajadores (a) al liberar temporalmente a la empresa deudora de ejecuciones judiciales de cualquier tipo, con excepción de "los juicios laborales sobre obligaciones que gocen de preferencia de primera clase, suspendiéndose en este caso solo la ejecución y realización de bienes del Deudor" (art. 57, $\mathrm{N}^{\circ} 1$, letra a), y (b) al mantener vigentes -entre otros- los contratos de trabajo, por la vía de señalar en forma genérica que "todos los con-

\footnotetext{
* Profesor de Derecho Comercial, Universidad de los Andes, Chile (Av. Monseñor Álvaro del Portillo 12455, Las Condes, Santiago). Doctor en Derecho, Universidad de Valencia, España. Email: ejequier@uandes.cl
} 
tratos suscritos por el deudor mantendrán su vigencia y condiciones de pago" (art. 57, $\mathrm{N}^{\circ}$ 1 , letra c).

A diferencia de lo que ocurre con el resto de los acreedores de la empresa, además, la situación de los trabajadores es especialmente compleja en estos casos, pues, más allá del impago salarial, en ocasiones su iniciativa para ejercer acciones judiciales se ve menoscabada por el interés de mantener sus puestos de trabajo. Enfrentado a la contingencia de perder su fuente de ingresos, por ende, el trabajador se abstendrá -por regla general- de judicializar su situación, a menos que esa pérdida sea ya inevitable e inminente. En otros casos, en cambio, la ausencia de una regulación clara puede servir como incentivo para propiciar, incluso por vías de hecho, un despido que resulte económicamente más atractivo que la permanencia en el cargo, con la consiguiente carga financiera adicional para el empleador que aspira a reorganizar sus pasivos.

De allí, entonces, la importancia de una regulación legal que recoja esta realidad y que equilibre los intereses concurrentes desde la óptica del Derecho concursal. A fin de cuentas, la incertidumbre respecto de la continuidad laboral, la sensación de indefensión frente al impago de las remuneraciones adeudadas o, en fin, el simple interés en un pronto despido de cara al pago de una indemnización por años de servicio, son terreno fértil para el surgimiento de medidas de autotutela por parte de los trabajadores, justificadas o no. Todavía más, en un diseño como el de la LC, en donde el presupuesto objetivo de la apertura del concurso se muestra especialmente difuso y hasta ausente en el procedimiento de reorganización judicial, la falta de una concreta regulación de la situación de los trabajadores y de los créditos laborales constituye, en el otro extremo, un nutriente privilegiado para eventuales abusos del empleador, quien en ciertos extremos podría aliviar sin mayor costo su carga laboral con el pretexto de una reorganización, sin estar realmente en insolvencia.

Por lo anterior, el presente estudio apunta a identificar las consecuencias jurídicas, económicas e incluso sociales que genera el diseño del procedimiento de reorganización en la Ley $\mathrm{N}^{\circ} 20.720$, caracterizado por la aparente exclusión de los créditos laborales en el procedimiento de reorganización ${ }^{1} \mathrm{y}$, adicionalmente, por la desatención del interés que tienen los trabajadores en los efectos y alcances de un eventual acuerdo entre el empleador y sus acreedores. Se revisarán, además, los distintos mecanismos implementados en el derecho comparado para la solución de esta problemática, ideados - muchos de ellos- a partir de propuestas de derecho uniforme y/o, simplemente, de la incorporación al derecho interno de normas o principios consignados en normativas comunitarias y en convenios internacionales.

\footnotetext{
1 Decimos que la exclusión es aparente, pues, a nuestro juicio, los créditos de la primera clase, como los de cuarta, sí están -y deben estar- comprendidos en el Procedimiento Concursal de Reorganización. Sobre el particular, nuestra ponencia: "Primera clase de créditos: ¡̇la gran ausente en el procedimiento de reorganización judicial, ley N²0.720?”, VIII Jornadas Chilenas de Derecho Comercial, Pontificia Universidad Católica de Valparaíso, 7 y 8 de septiembre de 2017.
} 


\section{SÍNTESIS DE ASPECTOS RELEVANTES DEL PROCEDIMIENTO DE REORGANIZACIÓN EN LA LEY 20.720}

Para contextualizar el análisis que se inicia, y como ejercicio orientado a incardinar en él la situación jurídica en que se encuentran actualmente los créditos laborales y los trabajadores de la empresa deudora en reorganización, resulta necesario destacar previamente algunos aspectos estructurales de dicho mecanismo en el diseño de la LC.

La Ley $\mathrm{N}^{\circ} 20.720$, que "sustituye el régimen concursal vigente por una ley de Reorganización y Liquidación de empresas y personas, y perfecciona el rol de la Superintendencia del ramo", marca una nueva etapa en el Derecho concursal chileno, que a partir de la primera década del siglo XXI muestra una marcada tendencia en pro de la reestructuración de aquellas empresas insolventes aunque económicamente viables².

En este contexto jurídico-económico, permeado por la opción pro reorganización y continuidad de la empresa económicamente viable y de su administración, los trabajadores mantienen su vinculación laboral con el ente concursado, en el entendido que aquellos constituyen un elemento indispensable para el éxito de cualquier acuerdo que involucre continuidad empresarial. Sin embargo, la LC omite toda y cualquier referencia directa a los trabajadores en el procedimiento de reorganización, generando -al menos hasta aquí- una situación de incertidumbre frente a los alcances y efectos de un acuerdo fraguado en un ámbito de negociación en el que aquellos no han participado y que, por lo mismo, les resulta ajeno y hasta hermético.

\section{LA AUSENCIA DE PRESUPUESTO OBJETIVO EN LA REORGANIZACIÓN Y SU INCIDENCIA EN LAS RELACIONES Y CRÉDITOS LABORALES \\ Una primera característica de la LC, que se manifiesta nítidamente en el procedi-} miento de reorganización, es la muy notoria ausencia de disposiciones que se refieran a la insolvencia de la empresa deudora, como presupuesto material indispensable que legitime y justifique su aplicación. Es más, la LC menciona la palabra "insolvencia" solo para referirse a la "Superintendencia de Insolvencia y Reemprendimiento" o al "Superintendente de Insolvencia y Reemprendimiento", y en el Capítulo VIII al tratar la Insolvencia Transfronteriza, sin ocuparse de ella en el resto de su articulado.

Adicionalmente, el artículo 2.1 de la LC define el acuerdo de reorganización judicial como aquel destinado a "reestructurar sus activos y pasivos", lo que reitera luego en el art. 60 cuando señala que el acuerdo de reorganización puede consistir en "cualquier objeto tendiente a reestructurar pasivos y activos de la Empresa Deudora". Nada dice, sin embargo, respecto del fin último que deben perseguir esas reestructuraciones de activos y pasivos, que no puede ser otro que la superación de una situación profunda y permanente de imposibilidad de pago de las obligaciones del ente concursado, actual o potencial. Podrá

\footnotetext{
2 Una manifestación clara de este nuevo escenario normativo -aunque no la primera- es el artículo $11^{\circ}$ la LEY $\mathrm{N}^{\circ}$ 20.416, inserta en un contexto legislativo más amplio conocido como "Estatuto de las Empresas de Menor Tamaño", que incorpora al ordenamiento jurídico chileno todo un aparataje extrajudicial para la solución de la insolvencia, diseñado para $-\mathrm{y}$ ajustado a- la realidad de las micro y pequeñas empresas.
} 
decirse, acaso, que la insolvencia de la empresa deudora que se somete a reorganización se encuentra implícita en la estructura de la ley, por cuanto el destino natural de una reorganización frustrada es siempre la liquidación. Sin embargo, lo concreto es que la LC no contempla requisito o barrera material alguna de acceso al procedimiento concursal de reorganización, que restrinja y reserve su aplicación a aquellos casos de real insolvencia, actual o inminente. Únicamente, la ley se limita a regular unos requisitos formales para la respectiva solicitud de inicio del procedimiento (art. 54) y a listar los antecedentes que el solicitante debe acompañar luego al proceso (art. 56); pero lo cierto es que ninguno de ellos, ni todos juntos, permiten constatar fundadamente la existencia efectiva del señalado presupuesto objetivo.

Para cerrar este panorama, la LC tampoco proporciona un estadio procesal que permita revisar la concurrencia -o no- de la insolvencia de la empresa deudora, lo que implica que la sola solicitud del deudor se erige en una suerte de presunción iure et de iure de insolvencia, sustentada en una confesión de aquel que, atendida la estructura del procedimiento, no admite prueba en contrario. Y como broche final, la ley tampoco permite impugnar la resolución de reorganización, a que se refiere el art. 57.

Todo lo dicho, en fin, configura un escenario potencialmente adverso para los trabajadores, quienes en ciertos extremos y dada la predicha dilución del presupuesto objetivo, pueden verse afectados por una instrumentalización abusiva del procedimiento de reorganización. Al no existir barreras de entrada ni mecanismos de revisión jurisdiccional del señalado presupuesto material, en efecto, el mecanismo concursal queda expuesto a maniobras capaces de desnaturalizar por completo su sentido y finalidad; y entre ellas, precisamente, destaca la posible elusión del cumplimiento de sus obligaciones laborales por parte del ente concursado, como propósito verdadero aunque encubierto. Así lo advierte expresamente la Guía Legislativa CNUDMI, sobre el Régimen de Insolvencia ${ }^{3}$, cuando señala:

“46. (...) En algunos países no se exige que se cumpla ningún criterio sustantivo específico, sino que el deudor podrá presentar su solicitud [de reorganización] cuando lo estime oportuno; solo se le exige que presente una simple solicitud ante el tribunal competente $(. .$.$) .$

47. Cabe señalar que un criterio de apertura menos estricto puede inducir al deudor a abusar del procedimiento de insolvencia. Por ejemplo, podría suceder que un deudor solicitara la apertura de un procedimiento sin estar en dificultades financieras y presentara un plan de reorganización que le permitiera eludir ciertas obligaciones onerosas, como contratos laborales, renegociar su deuda o recurrir a evasivas y privar con ello a sus acreedores del pago puntual y completo de sus deudas. (...) El riesgo de que un deudor abuse así de un procedimiento de reorganización dependerá del criterio exigido para su apertura, de cómo se haya de preparar el plan de reorganización, del control que se le deje al deudor de su negocio tras la apertura del procedimiento y de las sanciones previstas contra todo recurso indebido a este procedimiento (...). Para evitar que el deudor recurra indebidamente al procedimiento, el régimen de la insolvencia podría, por ejemplo, disponer que el foro competente esté facultado para desestimar la solicitud presentada y que, en tal caso, el deudor

3 Guía Legislativa de la CNUDMi sobre el Régimen de la Insolvencia (2006) p. 65. 
incurra en responsabilidad frente a sus acreedores por los gastos dimanantes del procedimiento y por todo daño ocasionado que sea imputable a la solicitud presentada”.

No nos parece acertado, entonces, aquel diagnóstico invocado durante el trámite parlamentario y que justificó la completa exclusión de los trabajadores de la empresa deudora en la circunstancia de que, por el hecho de ser tales, las estipulaciones del acuerdo de reorganización no les empecen jurídicamente ${ }^{4}$. Al contrario, resulta hasta evidente que la restructuración de una empresa sí puede afectar la situación laboral de sus trabajadores, quienes quedan expuestos a una eventual reubicación a otras áreas, al cambio de funciones, modificación de remuneraciones y, en un extremo, al despido 5 . Como apuntan Rivero y $\operatorname{Largo}^{6}$, "una reorganización o reestructuración de empresa es una situación que excede de las decisiones de gestión ordinarias, de modo que importará cambios relevantes en la organización productiva y en los procesos de trabajo"; y en este contexto, por ende, los diversos intereses involucrados en la reorganización deben articularse a través de herramientas concursales que incorporen y compatibilicen principios, bienes jurídicos y normas de variada índole (comercial, tributaria, societaria, laboral, etc.), todas ellas permeadas por un fin común de superación de la insolvencia y, en lo que aquí interesa, de tutela proporcionada de los derechos de los trabajadores del empleador concursado.

La ley concursal, en fin, debe contemplar los necesarios resguardos de cara a las relaciones laborales que puedan resultar afectadas por un acuerdo entre el deudor y sus acreedores, asignándole además el carácter de acreedores a aquellos trabajadores o ex trabajadores que son titulares de créditos laborales anteriores a la resolución de reorganización.

\section{El MODELO DE PROPUESTA POR CLASE O CATEGORÍA DE ACREEDORES. SITUACIÓN DE LOS CRÉDITOS LABORALES PREFERENTES}

Como se dijo supra, durante la discusión del proyecto en las Comisiones Unidas de Economía y Constitución del Senado se dejó en claro que el acuerdo de reorganización judicial no afecta a los trabajadores ${ }^{7}$. Por ello, al diseñarse el nuevo régimen de acuerdos por clases o categorías de acreedores se hizo hincapié solo en las dos a que refiere el art. 61 de la LC, esto es, una clase para los acreedores valistas o quirografarios y otra para los de segunda y tercera clase, prendarios e hipotecarios, lo que dejó sin una regulación normativa concreta a los créditos de la primera clase.

Nada se dijo, entonces, respecto de los créditos laborales de primera clase, a que se refieren los numerales $5^{\circ}$ y $8^{\circ}$ del art. 2472 del Código Civil, lo que ha llevado a alguna doctrina $^{8}$ a sostener que dichos créditos no son "reorganizables" y que, por lo mismo, los trabajadores y ex trabajadores de la empresa deudora han sido relegados a los extramuros del procedimiento de reorganización. Reiteramos, con todo, que esta omisión normativa no es sinónimo de exclusión, de manera que la primera clase, al igual que la cuarta, sí de-

\footnotetext{
Véase la Historia de la Ley Nº 20.720 (2014) p. 704.

Sierra (2016) p. 231.

6 Rivero y Largo (2010) p. 17.

7 Véase Historia de LA LEy Nº 20.720 (2014) p. 704.

Puga Vial (2014) p. 207.
} 
ben ser considerados en el Procedimiento Concursal de Reorganización (vid. nota al pie $\mathrm{N}^{\circ} 1$ ).

Distinta era la situación durante la derogada LQ, incorporada al Libro IV del C. de Com., pues allí los créditos preferentes -entre ellos los laborales hasta por el límite legalpodían optar entre votar o no la propuesta de convenio judicial preventivo, entendiéndose que el solo hecho de hacerlo implicaba una renuncia a las respectivas preferencias y, por ende, la inclusión de dichos créditos en el cómputo del pasivo valista (arts. 190 y 191 LQ).

El escenario normativo actual, entonces, afecta en último término la eficacia misma de la reorganización como herramienta concursal, con consecuencias negativas que se han hecho sentir con fuerza en el terreno de su aplicación práctica.

\section{TRABAJADORES Y REORGANIZACIÓN EN EL DERECHO COMPARADO. BREVE SÍNTESIS}

Son varias las legislaciones extranjeras que se han hecho cargo de la situación de los trabajadores de la empresa en concurso, mediante fórmulas orientadas a equilibrar la tutela de todos los intereses afectados por la insolvencia del deudor-empleador en reorganización. En lo que sigue, nos detendremos en el análisis de aquellas normativas concursales que nos han parecido más relevantes y proactivas sobre este punto en Latinoamérica, Brasil y en el derecho europeo comunitario e interno.

1. El caso uruguayo: Ley N¹8.387/2008, de 23 de octubre, sobre "Declaración Judicial del Concurso y Reorganización Empresarial"

La situación al trabajador ha merecido una atención especial en la ley concursal uruguaya, $\mathrm{N}^{\circ} 18.387$ del año 2008, la que contempla básicamente tres mecanismos que apuntan a la protección de los derechos de los trabajadores de la empresa deudora insolvente: (a) el denominado "pronto pago" de aquellos créditos laborales no cuestionados; (b) la posibilidad de que los acreedores laborales puedan ocuparse de la continuidad empresarial en el caso de las cooperativas o en los casos de abandono de la empresa; y (c) la continuidad de los contratos de trabajo y de las condiciones laborales en caso de enajenación de la empresa "en bloque". Analizaremos cada instituto por separado.

\subsection{En cuanto al "pronto pago" de los acreedores laborales}

Según el art. 62 de la Ley $\mathrm{N}^{\circ} 18.387$, modificado por la Ley $\mathrm{N}^{\circ} 18.593$, de 14 de octubre de 2009, si la empresa concursada está en marcha -cuyo es precisamente el caso de aquellas sujetas a reorganización-, el Síndico o el Interventor están obligados a proceder al "pronto pago" de los créditos laborales, en la medida en que haya fondos disponibles para ello y que los créditos referidos no se encuentren prescritos. Como explica Martínez ${ }^{9}$, entonces, para que esa obligación de realizar el "pronto pago" se ponga en práctica se requiere:

a) que existan recursos líquidos suficientes (dinero disponible) o bienes fácilmente realizables;

Martínez (2012) pp. 277 y ss. 
b) que en ambos casos, el hecho de disponer del dinero o de los bienes "no afecte la viabilidad de la continuación del giro del deudor", otorgando con ello una notoria prioridad al principio de "conservación de la empresa", por sobre la "defensa del trabajador".

c) que exista una previa autorización judicial, a requerimiento exclusivo de Síndicos o Interventores;

d) que no estuvieran prescritos los créditos laborales que se deban pagar; y

e) que los créditos laborales surjan de la documentación del empleador y "no existan dudas razonables sobre el origen y la legitimidad de los mismos" (artículo 62 inciso 3), pues solo en ese caso no será necesaria la verificación previa ni una sentencia laboral que los reconozca.

\subsection{Prioridad de los trabajadores para la adquisición de la empresa subastada "en bloque"}

En los países anglosajones, la figura del Leveraged buy-out -o adquisición de empresas- es común y ampliamente reconocida. Entre sus variantes, y en lo que aquí interesa, se permite que los trabajadores de la empresa en crisis puedan adquirirla y hacerse cargo de su gestión, como fórmula de salvataje de la misma y, consecuencialmente, de sus fuentes de trabajo. En esta modalidad, conocida como Leveraged Employee buy-out o "compra apalancada de los empleados", la adquisición se verifica mediante la capitalización de los créditos laborales exigibles, de manera tal que, de acreedores, los trabajadores pasan a ser socios o cooperados de la nueva persona jurídica adquirente.

En conformidad al art. 172 letra b) de la Ley $\mathrm{N}^{\circ} 18.387$, en caso de enajenarse la empresa en funcionamiento mediante proceso licitatorio, "Podrán formularse ofrecimientos por parte de la cooperativa o sociedad comercial de trabajadores de la empresa subastada que se constituya y esté integrada de forma tal que más del 50\% (cincuenta por ciento) de la propiedad correspondiera a los trabajadores que desarrollaban actividad personal en la misma en el inicio del proceso concursal y que, en caso de adoptar la forma de sociedad anónima o en comandita por acciones, las acciones de los trabajadores sean nominativas no endosables." Asimismo, la ley permite que los créditos laborales se imputen al precio de la subasta, al señalar que la oferta podrá incluir la renuncia de dichos créditos y de las indemnizaciones por el seguro de desempleo que eventualmente corresponda. La oferta formulada por esta cooperativa o sociedad comercial, además, "tendrá preferencia por sobre los restantes oferentes en caso de igualdad de condiciones propuestas"10.

\footnotetext{
10 Este mecanismo no es exclusivo de la legislación uruguaya, ni menos una creación propia. Así lo deja en claro el Convenio de la OIT de 1991, sobre "Protección de los créditos laborales en caso de insolvencia del empleador", al señalar que "En muchos países puede apreciarse una tendencia a la adquisición o la gestión temporaria de la empresa en dificultades por sus propios asalariados. Más aún, en muchos países han surgido fórmulas jurídicas, tales como las ESOP (Employee Stock Ownership Programme) de los Estados Unidos, las sociedades anónimas laborales en España o las SCOP (Sociedades cooperativas obreras de producción) en Francia, para facilitar las operaciones de ese tipo".

- Véanse además los artículos 13 y ss. del Convenio OIT N¹58, sobre la terminación de la relación de trabajo, y la Recomendación №166 sobre el mismo tema, ambos de 1982). Todavía más, el art. 1613 del Código de Comercio de Bolivia, del año 1977, establece un derecho de preferencia de los trabajadores para adquirir la empresa en caso de enajenación de la unidad económica o como conjunto de bienes, que integren un estable-
} 
Más aún, si la venta en bloque de la empresa fracasa finalmente, el art. $174 \mathrm{~N}^{\circ} 2$ de la ley permite todavía que el juez, previa vista al síndico, designe como depositaria de los bienes de la empresa, con facultades de uso precario de los mismos, "a una cooperativa de trabajo que se constituya con la totalidad o con parte del personal”, agregando luego que "Los créditos laborales privilegiados que pudieren existir en la masa del concurso serán compensados y computados como aporte de los trabajadores a la cooperativa constituida"11.

Por último, el art. 238 establece que los trabajadores pueden solicitar judicialmente la aplicación del art. $174 \mathrm{~N}^{\circ} 2$, en aquellos casos de abandono de la empresa en que el deudor no se hubiere presentado a promover su propio concurso, existiendo solo acreedores laborales.

\subsection{Venta "en bloque" y continuidad de los contratos de trabajo}

La doctrina mayoritaria en Uruguay considera que en la venta en bloque de la empresa van incluidas las relaciones laborales del empleador-enajenante ${ }^{12}$ y que, por ende, los contratos de trabajo continúan en principio con el nuevo empresario. Los principios de la ley $\mathrm{N}^{\circ} 18.387$-dicen Rosenbaum Rimolo y Castello ${ }^{13}$ - tienden a la conservación de los puestos de trabajo, de manera que, en la valorización económica de la empresa que se vende en bloque, las condiciones, términos y antigüedad de la relación laboral se mantienen incólumes.

Distinta es la situación de las deudas laborales que registre la empresa cuyo establecimiento de comercio se vende "en bloque", pues, en virtud del art. 177, "No será de aplicación al adquirente de los activos del deudor, del establecimiento o de la explotación del deudor, enajenados en el proceso de liquidación de la masa activa, la responsabilidad que la ley pone a cargo de los sucesores o adquirentes por obligaciones comerciales, laborales, municipales, tributarias o de cualquier otra naturaleza." La empresa, pues, se adquiere sin deudas.

\section{Sistema CONCURSAL ARGENTINO}

En la "Ley de Concursos y Quiebras" argentina, N²4.522 de 20 de julio de 1995, los trabajadores de la empresa concursada tienen una activa participación en el procedimiento de convenio. Así queda en evidencia al revisar los siguientes ejemplos:

A) Por regla general, todos los acreedores deben verificar sus créditos, incluidos los laborales. Estos, sin embargo, están exentos del pago del arancel de verificación a que se refiere el art. 31 .

cimiento o sucursal susceptible de explotación unitaria. Si en tales casos -dice la norma-, "los trabajadores de la misma empresa constituyen sociedad o cooperativa para adquirirla, esta será preferida respecto de cualquier otro interesado en igualdad de condiciones".

11 En el mismo sentido, el art. 104 de la Ley URUGUAYA N ${ }^{\circ}$ 18.407, que regula el Sistema Cooperativo.

12 Por todos Miller (2008) pp. 99 y 103.

13 Rosenbaum y Castelo (2010) pp. 129 y 130. En contra López (2016) pp. 171-194. 
B) En conformidad al art. 41, el deudor debe presentar a la sindicatura y al juzgado una propuesta fundada de agrupamiento y clasificación en categorías de los acreedores verificados y declarados admisibles, la naturaleza de las prestaciones correspondientes a los créditos, el carácter de privilegiados o quirografarios, o cualquier otro elemento que razonablemente, pueda determinar su agrupamiento o categorización, a efectos de poder ofrecerles propuestas diferenciadas de acuerdo preventivo. "La categorización deberá contener, como mínimo, el agrupamiento de los acreedores en TRES (3) categorías: quirografarios, quirografarios laborales -si existieren- y privilegiados, pudiendo -incluso- contemplar categorías dentro de estos últimos."

C) Es el juez y no el deudor quien determina la categorización final de los acreedores, mediante resolución judicial (art. 42).

D) En la misma resolución mencionada en el literal precedente, el juez debe designar a los integrantes del denominado "Comité de control". Se trata de un órgano concursal con amplias facultades de información y consejo encargado de supervigilar-además- la etapa del cumplimiento del acuerdo preventivo, integrado por acreedores y por los representantes de los trabajadores (arts. 42 y 260).

E) La propuesta de convenio del deudor puede consistir, entre otras, en la capitalización de créditos "inclusive de acreedores laborales", en acciones o en un programa de propiedad participada (art. 43).

F) Congruente con lo anterior, y para facilitar la aprobación de la propuesta, la ley permite que los trabajadores puedan renunciar a los privilegios que provienen de la relación laboral, en una proporción no inferior al veinte por ciento (20\%) del crédito respectivo, debiendo ser ratificada dicha renuncia en audiencia ante el juez del concurso con citación a la respectiva asociación gremial, si fuere el caso (art. 43 inc. $10^{\circ}$ ). Con todo, si la propuesta es finalmente rechazada, "El privilegio a que hubiere renunciado el trabajador que hubiere votado favorablemente el acuerdo renace en caso de quiebra posterior con origen en la falta de existencia de acuerdo preventivo, o en el caso de no homologarse el acuerdo".

G) Vencido el período de exclusividad a que se refiere el art. 43, sin que el deudor haya obtenido las conformidades previstas para el acuerdo preventivo, existe todavía la posibilidad de evitar la declaración de quiebra por parte -entre otros- de las cooperativas de trabajo, conformada por trabajadores interesados en la adquisición de las acciones o cuotas representativas del capital social de la concursada, a efectos de formular una nueva propuesta de acuerdo preventivo (art. 48).

H) Como regla de general aplicación, y al igual que en la ley uruguaya, el sistema concursal argentino contempla la figura del "pronto pago". Según el art. 16 inc. $9^{\circ}$ de la ley “(...) Los créditos [laborales] serán abonados en su totalidad, si existieran fondos líquidos disponibles", agregando que "En caso contrario y hasta que se detecte la existencia de los mismos por parte del síndico se deberá afectar el tres por ciento (3\%) mensual del ingreso bruto de la concursada." Será obligación del síndico, además, confeccionar "un plan de pago proporcional a los créditos y sus privilegios, no pudiendo exceder cada pago individual en cada distribución un monto equivalente a cuatro (4) salarios mínimos vitales y móviles (...).” 


\section{Sistema CONCURSAl De Brasil}

En la legislación concursal brasileña, al igual que en las anteriores, los créditos laborales están sometidos también al procedimiento de reorganización judicial.

$\mathrm{El}$ art. 49 de la Ley $\mathrm{N}^{\circ} 11.101$, de 9 de febrero de 2005, que "Regula la recuperación judicial, extrajudicial y quiebra del empresario y la empresa de negocios", señala que están sujetos a reorganización todos los créditos del deudor, vencidos o no, incluidos -por endelos laborales ("Estão sujeitos à recuperação judicial todos os créditos existentes na data do pedido, ainda que não vencidos"). Por excepción, la ley establece que los créditos fiscales -y otras excepciones adicionales- no quedan comprendidos en el señalado procedimiento (art. 187).

Los trabajadores, además, forman una clase propia de acreedores, conjuntamente con los créditos provenientes de accidentes del trabajo, tanto en la asamblea general de acreedores (art. 35) como en el comité de acreedores (art. 26). Sus votos en la asamblea general son computados de manera unitaria o "por cabeza", independientemente del valor de sus respectivos créditos (art. $45 \mathrm{~N}^{\circ} 2$ ).

Adicionalmente, la ley contempla una serie de normas que apuntan, concretamente, a regular la situación de los trabajadores de la empresa deudora y el destino de los créditos laborales:

A) Se permite, en primer término, que el establecimiento comercial sea traspasado o arrendado a una sociedad constituida por los trabajadores (art. 50. VII).

B) Puede acordarse también una reducción salarial, compensación de honorarios y la reducción de la jornada laboral, mediante acuerdo o convenio colectivo (art. 50. VIII).

C) Se autoriza la formación de una sociedad de acreedores por los empleados, a la que se aportarán los bienes de la empresa deudora como pago total o parcial de los créditos adeudados (art. 50. XVI).

D) Recogiendo el criterio del "pronto pago", mencionado previamente, se establece que el plan de reorganización presentado por el deudor no puede prever un plazo superior a un año para el pago de los créditos derivados de la legislación laboral o provenientes de accidentes del trabajo, que estuvieren vencidos a la fecha de la solicitud de inicio del procedimiento.

Asimismo, el plan no puede contemplar un plazo superior a 30 días para el pago, hasta el límite de 5 salarios mínimos por trabajador, de los créditos de naturaleza estrictamente salarial vencidos durante los 3 meses anteriores a la solicitud de reorganización judicial (art. 54).

Por último, la jurisprudencia de los tribunales brasileños se encuentra dividida en la actualidad, en cuanto a la determinación del momento preciso que define la existencia de los créditos del trabajador y, por ende, la posibilidad de que estos sean incluidos en el proceso de reorganización judicial. Se ha entendido, por un lado, que dicho momento coincide con el incumplimiento de la relación de trabajo, reflejado en el impago de los salarios respectivos ${ }^{14}$; mientras que, en el otro extremo, se ha resuelto que dicho momentum

14 Por todas, sentencia TJRS 6a Cámara Civil (27 de agosto de 2015). En el mismo sentido: Sentencia TJSP, Cámara Reservada de Falencia y Recuperación (29 de marzo de 2011); Sentencia TJRJ, 4a Cámara Civil (20 de julio de 2010). 
será aquel en que los créditos respectivos han sido aceptados o reconocido como tales por el tribunal ${ }^{15}$.

\section{Sistema concursal de Perú}

En Perú, la "Ley General del Sistema Concursal", No 27.809 de 8 de agosto de 2002, contempla básicamente dos herramientas para abordar la situación de crisis de la empresa insolvente: a) El convenio de liquidación, bajo las modalidades de liquidación en marcha o continuidad de operaciones por un plazo determinado (going concern) y la liquidación ordinaria con suspensión de actividades; y b) el Plan de Reestructuración, que a su vez admite la modalidad de la reestructuración o reorganización en general y, además, la figura del Acuerdo Global de Refinanciación denominado Concurso Preventivo, caracterizado por su naturaleza concentrada o de tipo fast track, homologado por el "Instituto Nacional de Defensa de la Competencia y de la Protección de la Propiedad Intelectual" -INDECOPI- ${ }^{16}$.

Respecto del tratamiento de los trabajadores y créditos laborales en el procedimiento de reestructuración o reorganización -que en el caso peruano incluye también las deudas previsionales- el Capítulo V del Título II de la ley incluye las siguientes disposiciones relevantes:

A) Los créditos laborales participan en el procedimiento de reorganización y deben ser hechos valer en el mismo (art. 37.4 y art. 39.4).

B) En conformidad al art. 47.2, "Los créditos de remuneraciones y beneficios sociales serán representados [en la junta de acreedores] por quien o quienes designe el Ministerio de Trabajo y Promoción del Empleo (...).” El art. 40, a su vez, establece que "Para el reconocimiento de los créditos de origen laboral, la Comisión podrá aplicar el principio de la primacía de la realidad, privilegiando los hechos verificados sobre las formas o apariencias contractuales que sustentan el crédito".

C) Por otra parte, y de conformidad al art. 66.3, "El Plan de Reestructuración deberá incluir, bajo sanción de nulidad, un cronograma de pagos que comprenda la totalidad de las obligaciones adeudadas hasta la fecha de la difusión del concurso.” A continuación, y refiriéndose concretamente al tratamiento de los trabajadores en el referido plan, el art. 66.4 señala que "En dicho cronograma de pagos se deberá precisar, bajo sanción de nulidad del Plan, que de los fondos o recursos que se destinen al año para el pago de los créditos, por lo menos un $30 \%$ se asignará en partes iguales al pago de obligaciones laborales que tengan el primer orden de preferencia, (...)."

El artículo 69.2, a su vez, declara inválida la renuncia de preferencias hecha por acreedores laborales, en contraste con la opción del derecho argentino.

\footnotetext{
15 Sobre las posturas doctrinales y jurisprudenciales en esta materia puede consultarse a SCALZILLI et al. (2016) pp. 241-243.

16 Órgano administrativo encargado desde el Estado de la vigilancia de la aplicación de la ley concursal. Según el artículo X de la Ley concursal peruana, "El Estado, a través del INDECOPI, facilita y promueve la negociación entre acreedores y deudores, respetando la autonomía privada respecto de las decisiones adoptadas en los procedimientos concursales con las formalidades de ley".
} 


\section{Sistema concursal de Colombia}

La ley concursal colombiana, $\mathrm{N}^{\circ} 1.116$ de 2006, se ocupa también de la situación del trabajador de la empresa deudora en insolvencia.

A) En primer lugar, para acceder al régimen concursal de reorganización la ley exige que el deudor defina y explicite cuál es su pasivo por concepto de pensiones o cotizaciones previsionales. No exige, entiéndase bien, el pago efectivo de estas obligaciones como requisito de apertura del procedimiento. Únicamente, lo que se pide es que el deudor realice y tenga aprobado "el cálculo" de ese pasivo, que formará parte de la deuda reorganizable; aunque sí debe estar al día en el pago de las mesadas, bonos y títulos pensionales. Así lo señala el art. $10 \mathrm{~N}^{\circ} 3$, que hace referencia a dos situaciones distintas:

a) El empresario deudor debe estar al día con el pago de las mesadas pensionales vencidas, bajo la consideración de que esta acreencia es la primera en la escala de prelación de créditos y por tanto, si ni siquiera tiene para pagar mesadas pensionales, la empresa simplemente no es viable y no puede tramitar un proceso recuperatorio. Deberá ir a la liquidación.

b) El segundo aspecto consiste en que, si tiene a su cargo pasivo pensional a futuro, el cálculo actuarial debe estar aprobado y la fórmula de reorganización que se pacte debe contemplar la generación de los recursos necesarios para poder atender ese pasivo. Se trata, en fin, de estar al día con el pasado y tener claramente proyectado el futuro.

Por último, el art. 45.3 señala que el acuerdo de reorganización terminará anticipadamente "Por la no atención oportuna en el pago de las mesadas pensionales o aportes al sistema de seguridad social y demás gastos de administración".

B) Según el art. 27.1 "Los votos de las acreencias laborales serán las que correspondan a acreencias ciertas, establecidas en la ley, contrato de trabajo, convención colectiva, pacto colectivo o laudo arbitral, aunque no sean exigibles", dejando así en evidencia que los créditos laborales sí participan en el análisis del plan de reorganización y en su aceptación, modificación o rechazo final.

C) Se contempla una flexibilización relativa de la prelación de créditos, aunque con requisitos de tal entidad que la tornan compleja y de difícil implementación.

En conformidad al art. 13.7, la solicitud de admisión al procedimiento de reorganización debe incluir "Un proyecto de calificación y graduación de acreencias del deudor, en los términos previstos en el Título XL del Libro Cuarto del Código Civil (...), así como el proyecto de determinación de los derechos de voto correspondientes a cada acreedor." Sin perjuicio de lo anterior, el artículo $41 \mathrm{~N}^{\circ} 4$ establece que en el acuerdo puede modificarse la prelación de créditos siempre y cuando no se afecte por esa vía la prelación de créditos pensionales, laborales, de la seguridad social y adquirentes de vivienda. No obstante, la misma disposición permite que un pensionado o trabajador "acepte expresamente los efectos de una cláusula del acuerdo que verse sobre un derecho renunciable, siempre que ello conduzca a la recuperación de su crédito."

D) Se permite, en el art. 42, Parágrafo $2^{\circ}$, que los acreedores laborales capitalicen sus créditos en la empresa deudora siempre y cuando sus titulares convengan, individual y expresamente, las condiciones, proporciones, cuantías y plazos en que se mantenga o modifique, total o parcialmente, la prelación que le corresponde como acreencias privilegiadas. 
En caso de incumplimiento del acuerdo de reorganización -agrega la norma-, "los créditos laborales capitalizados recuperan la prelación de primer grado para efectos del acuerdo de adjudicación y el de liquidación judicial."

\section{LEGISLACIÓN CONCURSAL EUROPEA}

En esta parte del estudio, ahondaremos en la perspectiva europea con miras a identificar las diversas tendencias legislativas que se dan en este contexto. El caso español será la principal pauta de referencia, dado el énfasis que pone en esta materia; pero también se tratará el estado de la cuestión en el marco de la Unión Europea, dando unas pinceladas de lo que sucede en algunos países de su entorno que también han atendido particularmente esta materia, como Francia y Portugal.

\subsection{Derecho de la Unión Europea}

La norma de referencia a nivel comunitario es la Directiva 2008/94/CE del Parlamento Europeo y del Consejo, de 22 de octubre de 2008, relativa a la protección de los trabajadores asalariados en caso de insolvencia del empresario (DO 28.10.2008).

Esta Directiva obliga a los países de la Unión Europea a adoptar medidas necesarias para que las instituciones de garantía aseguren el pago de los créditos pendientes de los trabajadores asalariados (art. 3) ${ }^{17}$. Dicha obligación de pago puede ser limitada por los Estados Miembros, aunque con ciertos topes mínimos; y los empresarios, a su vez, deben contribuir a la financiación de dichas instituciones, salvo que estén garantizadas íntegramente por los poderes públicos (art. 5).

En cuanto al ámbito subjetivo, la Directiva se aplica en favor de todos los trabajadores asalariados según las respectivas legislaciones internas (art. 2). Existe una salvedad para el caso que en la legislación nacional de que se trate se excluya al personal doméstico al servicio de una persona física y el caso de los pescadores remunerados (art. 1.3), en cuyo caso se podrán seguir excluyendo.

Si la actividad del empresario insolvente se lleva a cabo en los territorios de al menos dos países de la UE, la autoridad competente para el pago de los créditos es la del país donde el trabajador ejerce habitualmente su trabajo.

Asimismo, el alcance de los derechos de los trabajadores ante las instituciones de garantía está determinado por el derecho nacional que se aplique en la institución de garantía.

17 En Italia, los créditos de los trabajadores gozan de prioridad frente a los de los demás acreedores. El trabajador puede recurrir al INPS (Istituto Nazionale della Previdenza Sociale) pidiendo al Fondo de Garantía de este organismo que proceda al pago de la indemnización por despido y las últimas tres mensualidades. Para que intervenga el Fondo se establecen tres requisitos: 1) cese de una relación de trabajo (dimisión, despido...); 2) apertura de un procedimiento concursal; y 3) existencia de un crédito por indemnización por fin de contrato (TFR o Trattamento di fine rapporto) sin resolver. No obstante, el Fondo también puede intervenir en el caso de un empresario no sujeto a procedimiento concursal en determinados casos. En la misma línea, en Alemania se establecen instituciones de garantía de los salarios, que incluyen diversos conceptos correspondientes a un período de referencia, regulados concretamente en el Capítulo tercero del Código Alemán de la Seguridad Social $(S G B)$. En España opera el FOGASA, al que se hará referencia en el texto. 
Se establece, además, un período de garantía mínimo, que se concreta en la remuneración de los tres últimos meses, en un período de referencia de al menos seis meses; o de ocho semanas, en un período de referencia de al menos dieciocho meses.

\subsection{El caso español}

La Ley Concursal No 22/2003, de 9 julio (en adelante LC), ha tomado en especial consideración la situación de los trabajadores de la empresa insolvente, articulando para ello diversos mecanismos de tutela y garantía que resultan comunes a los diferentes procedimientos concursales regulados en la ley. En su Disposición Final 14a , la LC introdujo además una importante modificación en el Estatuto de los Trabajadores, incorporando al mismo una nueva sección 5a del Capítulo III del Título I, relacionada con el procedimiento concursal, y un art. 57 bis nuevo, que señala: "En caso de concurso, a los supuestos de modificación, suspensión y extinción colectivas de los contratos de trabajo y de sucesión de empresa, se aplicarán las especialidades previstas en la Ley Concursal".

\subsubsection{Situación de los créditos laborales}

Respecto de la protección de las remuneraciones salariales, el ordenamiento jurídico español distingue entre los siguientes supuestos:

A) Créditos contra la masa (art. 84 LC):

Según el art. 84.2.1., son créditos contra la masa los "salarios por los últimos treinta días de trabajo efectivo anteriores a la declaración de concurso y en cuantía que no supere el doble del salario mínimo interprofesional." Gozan de preferencia para el cobro frente a cualquier otro crédito y se pagarán de forma inmediata (art. 84.3).

B) Créditos concursales:

Se consideran aquí las restantes deudas salariales.

C) Normas específicas:

a) Créditos con privilegio especial:

Se consideran tales los salarios de los trabajadores respecto de los objetos por ellos elaborados, mientras sean propiedad o estén en posesión del concursado (art. 90 LC).

b) Créditos con privilegio general:

Se trata de los salarios devengados con anterioridad a la declaración de concurso, que no disfruten del privilegio especial anterior (art. 91 LC), con un límite equivalente al triple del salario mínimo interprofesional multiplicado por el número de días pendientes de pago.

\subsubsection{Inclusión de los créditos laborales en la "Lista de Acreedores"}

Al igual que en las legislaciones analizadas supra, la LC española es explícita al momento de considerar a los trabajadores como acreedores del concurso, cuyos créditos deben incluirse por ende en la denominada "Lista de Acreedores" (art. 94.2.1 LC). Por lo anterior, todas las normas sobre participación en la Junta de Acreedores en la fase de Convenio (Sección $5^{\mathrm{a}}$ ) y derecho a voto, son aplicables también a los trabajadores por sus créditos.

Cosa distinta es el alcance que tiene el convenio aprobado respecto de los acreedores laborales, cuyos privilegios solo se verán afectados si votaron a favor de la propuesta o cuando concurren las mayorías a que se refiere la ley (art. 134 LC). 


\subsubsection{Caso de venta como unidad productiva}

En conformidad al art. 100.2 de la LC, la propuesta de convenio puede considerar la enajenación, bien del conjunto de bienes y derechos del concursado afectos a su actividad empresarial o profesional o de determinadas unidades productivas a favor de una persona natural o jurídica determinada. En tales casos, la misma norma aclara que tales propuestas "incluirán necesariamente la asunción por el adquirente de la continuidad de la actividad empresarial o profesional propia de las unidades productivas a las que afecte. En estos casos, deberán ser oídos los representantes legales de los trabajadores.”

\subsubsection{Concurso y medidas colectivas}

El artículo 64 de la LC se refiere a los procedimientos relacionados con la situación de los trabajadores del deudor concursado, que se pueden iniciar simultáneamente ante el mismo juez que conoce del concurso. Concretamente, el precepto referencia cuatro asuntos principales, todos ellos de carácter colectivo:

a) modificación sustancial de las condiciones de trabajo de carácter colectivo,

b) traslado colectivo,

c) despido colectivo y de suspensión colectiva de contratos y

d) reducción de jornada.

De todas ellas, la más frecuente en la práctica es la medida relativa a los despidos colectivos ${ }^{18}$. Las modificaciones de carácter individual o plural, por contrapartida, no son de competencia del juez del concurso; pero la administración concursal, como apunta Pardo, "deberá modular las causas en relación al propio concurso"19.

Por su parte, y de conformidad al art. 8.2 LC, es competente para conocer de estas medidas el mismo juez del concurso, quien conocerá de ellas de manera exclusiva. La resolución que adopte, sin embargo, se puede impugnar ante la jurisdicción social a través del recurso de suplicación (art. 64.8 LC).

Las medidas de carácter individual, por su parte, serán competencia de la jurisdicción laboral (es decir, quedan al margen de la LC), salvo en el aspecto de la ejecución, donde sí es competente el juez mercantil. El papel que tienen los representantes de los trabajadores en estos casos es fundamentalmente informativo.

\subsubsection{Aspectos comunes de las medidas colectivas.}

Cualquiera que sea la medida colectiva de que se trate, de las mencionadas en el art. $64 \mathrm{LC}$, todas ellas comparten ciertos aspectos que les son comunes:

18 La LC considera que el despido tendrá ese carácter en atención al número de trabajadores separados, esto es: a) Empresas de hasta 100 trabajadores: 10 trabajadores; b) Empresas de entre 100 y 300 trabajadores: 10\% de los trabajadores; c) Empresas de más de 300 trabajadores: 25\% de los trabajadores. Como señalan Mercader y Alameda, "el límite numérico fijado en la Ley Concursal (art. 64.10) es bastante similar (no idéntico) al establecido en la legislación laboral para extinciones, traslados y modificaciones sustanciales de las condiciones de trabajo -colectivas- (...) la razón de esta previsión normativa no es otra que evitar que una serie de rescisiones contractuales en cadena con alta indemnización puedan poner en peligro la viabilidad de la empresa y del empleo y, además, escapar al control del juez del concurso" (Mercader y Alameda [2012] p. 21). Sobre las medidas colectivas puede consultarse también a Prendes y Muñoz (2012) pp. 996 y ss.

19 PARdo (2008) p. 91. 
A) Legitimación para solicitar al juez del concurso una medida colectiva.

Pueden solicitar una medida colectiva la administración concursal, el empresario deudor y, en lo que aquí interesa destacar, los trabajadores de la empresa a través de sus representantes, tanto legales como sindicales (art. 64.2 LC). Los trabajadores podrán tener legitimación directa en el caso del art. 64.10 LC, esto es, cuando un grupo de trabajadores que superen los umbrales que indica ese precepto interpongan juntos una demanda de resolución de contrato ex art. 50 del Estatuto de los Trabajadores -ET-.

B) Causas válidas para adoptar las medidas colectivas.

La LC no se pronuncia al respecto, aludiendo simplemente a las "causas motivadoras”. Por otra parte, en el derecho español la mera declaración del concurso no es causa por sí misma de terminación del contrato de trabajo, de manera que, atendido el carácter supletorio del ET, para definir las causas que validan la adopción de medidas laborales colectivas en el concurso hay que acudir a aquellas consignadas en el referido cuerpo legal, esto es, a las causas económicas, técnicas, organizativas o de producción, a que se refiere el art. 51.1 del ET:

a) Las causas técnicas se configuran cuando se producen cambios, entre otros, en el ámbito de los medios o instrumentos de producción;

b) Las causas organizativas cuando se produzcan cambios, entre otros, en el ámbito de los sistemas y métodos de trabajo del personal o en el modo de organizar la producción;

c) Las causas productivas cuando se produzcan cambios, entre otros, en la demanda de los productos o servicios que la empresa pretende colocar en el mercado; y

d) En cuanto a las causas económicas, es preciso hacer algunas aclaraciones:

i. Término de contratos de trabajo.

Se puede adoptar esta medida cuando de los resultados de la empresa se desprenda una situación económica negativa, en casos tales como la existencia de pérdidas actuales o previstas o la disminución persistente de su nivel de ingresos ordinarios o ventas. En todo caso, se entenderá que la disminución es persistente si durante tres trimestres consecutivos el nivel de ingresos ordinarios o ventas de cada trimestre es inferior al registrado en el mismo trimestre del año anterior.

ii. Suspensiones y reducciones de jornada.

La suspensión de los contratos de trabajo es, por regla general, una medida que se adopta en el marco de la jurisdicción laboral, salvo que el empleador respectivo se encuentre en una situación de insolvencia. En este caso, el proceso judicial sigue siendo indispensable, pero la tramitación se radica ante el juez mercantil del concurso.

La declaración del concurso, por regla general, no supone la interrupción de la actividad de la empresa deudora. La excepción, dice Álvarez ${ }^{20}$ "es que por el juez del concurso se decretase el cese o la suspensión total o parcial de la actividad empresarial”.

La medida se justifica cuando de los resultados de la empresa se desprenda una situación económica negativa, en casos tales como la existencia de pérdidas actuales o previstas, o la disminución persistente de su nivel de ingresos ordinarios o ventas. En todo caso, se entenderá que la disminución es persistente si durante dos trimestres consecutivos el nivel de ingresos ordinarios o ventas de cada trimestre es inferior al registrado en el mismo trimestre del año anterior (art. 47.1 ET).

20 Áldvarez (2008) p. 111. 
iii. Modificaciones sustanciales de las condiciones de trabajo.

Se requerirá para ello la existencia de razones económicas, técnicas, organizativas o de producción que lo justifiquen. La precisión en este caso es que se consideraran tales las que estén relacionadas con la competitividad, productividad u organización técnica o del trabajo en la empresa, así como las contrataciones referidas a la actividad empresarial (arts. 40 y $41 \mathrm{ET})$.

C) Plan de viabilidad.

Es obligatorio acompañarlo a la solicitud de concurso cuando esta se efectúa por la administración concursal o por el empresario deudor, en caso que la medida afecte a empresas de más de 50 trabajadores (art. 64.5, párrafo $4^{\circ} \mathrm{LC}$ ). La finalidad de esta exigencia, como resulta evidente, apunta a incluir propuestas concretas por parte del deudor-empleador, que atenúen los efectos perjudiciales de las medidas laborales a adoptar.

D) Período de consultas.

La consulta con los representantes legales de los trabajadores es indispensable y deberá versar, como mínimo, sobre las posibilidades de evitar o reducir los despidos colectivos y de atenuar sus consecuencias mediante el recurso a medidas sociales de acompañamiento, tales como medidas de recolocación o acciones de formación o reciclaje profesional para la mejora de la empleabilidad (art. 51.4 ET). La consulta se llevará a cabo en una única comisión negociadora; pero si existen varios centros de trabajo, quedará circunscrita a los centros afectados por el procedimiento. En todo caso, la consulta puede ser sustituida por mediación o arbitraje, a solicitud de la administración concursal o de la representación de los trabajadores (art. 64.5 LC).

Por último, la administración concursal y los representantes de los trabajadores deberán comunicar al juez del concurso el resultado del período de consultas. Si no hay acuerdo, el juez debe dar audiencia a los intervinientes en el período de consultas para que formulen alegaciones e, incluso, aporten pruebas documentales (no se admiten otras). Comunicado el resultado del período de consultas, la autoridad laboral emitirá en el plazo de 15 días un informe sobre el acuerdo alcanzado o las medidas que han sido propuestas. El juez tendrá en cuenta este informe a efectos de emitir su resolución, en un plazo máximo de 5 días.

\subsubsection{Aspectos especiales de las medidas colectivas.}

La LC se ocupa de regular cuatro situaciones especiales relacionadas con las medidas colectivas mencionadas anteriormente.

A) Caso especial del art. 64.9 LC.

Se refiere a la suspensión del derecho a demandar la rescisión del contrato de trabajo en los términos del art. 41 del ET, en caso de acordarse una medida colectiva que involucre la modificación sustancial de las condiciones de trabajo y traslados colectivos. La suspensión abarca el periodo de tramitación del concurso y con el límite máximo de un año desde que se hubiere dictado el auto judicial que autorizó dicha modificación.

B) Caso especial del art. 64.10 LC.

Por regla general, los trabajadores podrán instar la extinción indemnizada del contrato de trabajo ex art. 50 ET. Sin embargo, el art. 64.10 LC señala que esas acciones individuales, motivadas por la situación económica o de insolvencia del concursado, "tendrán la 
consideración de extinciones de carácter colectivo" y se entenderán incluidas jurídicamente en el procedimiento de medida colectiva en curso, que ejerce aquí una suerte de vis atractiva ficta. De esta forma, la totalidad de esos procesos laborales individuales, posteriores a la solicitud del concurso y que se encuentren pendientes de resolución firme, "se suspenderán hasta que adquiera firmeza el auto que ponga fin al procedimiento de extinción colectiva", debiendo comunicarse además dicha suspensión a la administración concursal "a los efectos del reconocimiento como contingente del crédito que pueda resultar de la sentencia que en su día se dicte, una vez alzada la suspensión”.

Si la resolución del juez del concurso dispone la extinción de los contratos, la indemnización será de 20 días por año de servicio, con un tope de 12 mensualidades. En caso contrario -esto es, si el juez del concurso no dispone la extinción-, se reanudan las acciones individuales que estaban en suspenso en sede laboral, con un horizonte indemnizatorio sujeto al régimen común en caso de despido injustificado (33 días por año, con tope de 24 mensualidades).

C) Medidas colectivas adoptadas por el empresario sin autorización del juez del concurso.

A esto se refiere la Ley 36/2011, de 10 octubre, Reguladora de la Jurisdicción Social (LRJS), en sus arts. 124, 139 y 153. Si el empresario adopta las medidas colectivas que aquí se detallan sin la autorización del juez, los trabajadores tienen distintas opciones.

a) Si se trata de extinciones colectivas dispuestas por el empleador, estas pueden impugnarse colectivamente por los representantes de los trabajadores (art. 124.1 LRJS) o individualmente por los trabajadores afectados (art. 124.13 LRJS).

b) Las modificaciones sustanciales de las condiciones de trabajo, traslados, suspensiones, reducciones de jornada, etc., todas ellas colectivas, se pueden impugnar colectivamente por los representantes de los trabajadores (proceso de conflicto colectivo, art. 153 LRJS) o individualmente por los trabajadores afectados (art. 139 LRJS).

\subsubsection{Algunas consideraciones sobre el "Fondo de Garantía Salarial" (FOGASA)}

El FOGASA se encuentra regulado en el art. 33 del Estatuto de los Trabajadores y en el Real Decreto 505/1985, de 6 marzo, de "Organización y Funcionamiento del Fondo de Garantía Salarial.” Es un organismo autónomo, adscrito al Ministerio de Empleo y Seguridad Social, con personalidad jurídica propia, integrado por las aportaciones empresariales que son abonadas como "conceptos de recaudación conjunta", junto con las cuotas de Seguridad Social. Su finalidad es garantizar a los trabajadores el pago de los salarios pendientes a causa de insolvencia o concurso de su empleador-empresario, cuando los privilegios a que nos hemos referido en los apartados anteriores no son suficientes. Es decir, el FOGASA paga a los trabajadores como responsable subsidiario ${ }^{21}$ (art. 33.1 ET), pero también se con-

21 La responsabilidad directa, regulada inicialmente en el art. 33.8 ET, fue eliminada el 1 de enero de 2014. Se refería a las empresas de menos de 25 trabajadores, cuando se vieran afectadas por concurso, en cuyo caso el FOGASA debía pagar de forma directa al trabajador el $40 \%$ de la indemnización legal que correspondiera en caso de despido colectivo ex art. 64.2 LC, y lo hacía como si fuera una deuda propia. 
vierte en acreedor del empresario, dado que luego tiene derecho a reclamarle las cantidades anticipadas.

En cuanto a las prestaciones garantizadas y sus límites, la ley establece reglas distintas según cual sea la situación de los trabajadores:

A) Abono de salarios pendientes de pago a causa de insolvencia o concurso del empresario (art. 33.1 ET):

Se trata de las cantidades salariales a que se refiere el art. 26.1 ET y los salarios en tramitación ante la justicia competente, si procediese, con límite de 120 días y cada día hasta el doble del salario mínimo interprofesional diario, incluyendo la pagas extras (art. $33.1 \mathrm{ET})$.

B) Abono de ciertas indemnizaciones por fin de contrato (art. 33.2 ET):

Se trata concretamente de los supuestos contemplados en los arts. 50, 51 y 52 y de la extinción de contratos temporales, entre otros. El límite garantizado en este caso es de 1 año, y cada día hasta el doble del salario mínimo interprofesional diario (incluyendo pagas extras).

\subsection{El caso del derecho concursal francés ${ }^{22}$}

La legislación francesa, al igual que la española antes revisada, les asigna un rol activo a los trabajadores involucrados en el proceso de insolvencia de la empresa empleadora, tanto en el ámbito concursal como en las manifestaciones estrictamente laborales del señalado estado patrimonial.

\subsubsection{Normas concursales sobre los trabajadores de la empresa insolvente}

El Code de Commerce regula la insolvencia de la empresa en el Libro VI, "De las dificultades de las Empresas", artículos L611-1 y ss., y en lo que aquí concierne los procedimientos de conciliación, salvaguarda y saneamiento judicial de la empresa insolvente.

A) Procedimiento de conciliación.

El Título I trata "De la prevención y del arreglo amistoso de las dificultades de las empresas" y su Capítulo I, a su vez, contempla las disposiciones que dan forma al procedimiento de concil $n$ especial atención en la participación de los trabajadores durante su desarrollo e implementación.

Así, el art. L.611-9, introducido por la Ley No 2005-845 de 26 de julio de 2005, señala que "El Tribunal resolverá sobre la homologación [del acuerdo] tras haber oído o citado en debida forma para tomarles declaración a puerta cerrada al deudor, a los acreedores partes en el acuerdo, a los representantes del comité de empresa o, en su defecto, a los delegados del personal, al conciliador y al Ministerio Fiscal (...)”.

B) Procedimiento de Salvaguarda.

El Título II, por su parte, regula el procedimiento de "Salvaguarda", diseñado para superar la situación de aquellos comerciantes, artesanos, agricultores, personas físicas que ejerzan una actividad profesional autónoma y, en general, de cualquier persona jurídica de derecho privado, que presenten dificultades económicas susceptibles de conducirlos al esta-

22 La traducción de las normas legales que se citan corresponde al autor. 
do de insolvencia. En este procedimiento, nuevamente, los trabajadores tienen una activa participación:

a) El artículo L.621-1 del Code, introducido también por la Ley No 2005-845, señala en este caso que "El Tribunal decidirá sobre la apertura del procedimiento, tras haber oído o citado en debida forma para tomarles declaración a puerta cerrada al deudor y a los representantes del comité de empresa o, en su defecto, a los delegados del personal (...)”.

b) El art. L.621-4 establece que, en la resolución judicial de apertura y para efectos del denominado "periodo de observación" del deudor, el Tribunal solicitará al comité de empresa o, en su defecto, a los delegados del personal, que designen a un representante entre los trabajadores de la empresa. "En ausencia de comité de empresa o de delegado del personal -agrega la norma-, los trabajadores elegirán a un representante que ejercerá las funciones atribuidas a estas instituciones por las disposiciones del presente título. Las modalidades de nombramiento o elección del representante de los trabajadores serán precisadas por decreto adoptado en Conseil d'Etat". Tan relevante es esta intervención de los trabajadores que, a continuación, la misma disposición señala que "Cuando no se pueda nombrar o elegir ningún representante de los trabajadores, el empresario solicitará la declaración de insolvencia”.

c) Para decretar el cese parcial de la actividad de la empresa, la conversión del procedimiento de salvaguarda en uno de saneamiento judicial o, en último término, la liquidación de la empresa, el juez debe escuchar previamente, entre otros, "a los representantes del comité de empresa o, en su defecto, a los delegados del personal (...)”.

d) Los trabajadores o ex trabajadores no están obligados a verificar sus créditos anteriores a la resolución de apertura (art. L.622-24).

e) En cuanto al contenido del plan de salvaguarda, el art. L.6262, inciso $3^{\circ}$, establece que este "expondrá y justificará el nivel y las perspectivas de empleo así como las condiciones sociales previstas para el mantenimiento de la actividad". Asimismo, cuando el proyecto previera despidos por motivo económico, "indicará las medidas ya tomadas y definirá las acciones que se deban emprender con el fin de facilitar la recolocación y la indemnización de aquellos trabajadores cuyo puesto de trabajo se viera amenazado (...)". Lo mismo se reitera en el art. L.626-10.

f) Para aprobar el plan de salvaguarda, el tribunal debe oír previamente, entre otros, "a los representantes del comité de empresa o, en su defecto, a los delegados del personal" (art. L.626-9). Lo mismo para cualquier modificación sustancial de los objetivos o los medios del plan (art. L.626-26).

g) Por último, la ley es particularmente estricta cuando se trata del despido del representante de los trabajadores del deudor concursado. Dicho despido "será obligatoriamente sometido al comité de empresa, que emitirá su dictamen", y "solo podrá producirse con la autorización del inspector de trabajo del que dependa el establecimiento" (art. L.627-5).

C) Procedimiento de Saneamiento Judicial.

El Título III regula el "Saneamiento Judicial" (Redressement Judiciaire), arts. L.631-1 y ss., concebido para la reorganización o rescate del deudor insolvente, "que se encuentra en imposibilidad de hacer frente al pasivo exigible con el activo del que dispone" (art. L.631-1). En concreto, y según dispone el inciso $2^{\circ}$ de la misma norma, "El procedimiento de saneamiento judicial está destinado a permitir la continuidad de la actividad de la em- 
presa, el mantenimiento del empleo y la liquidación del pasivo", lo que involucra -nuevamente- la intervención directa de los trabajadores.

a) En primer término, el Code legitima activamente al comité de empresa o, en su defecto, a los delegados del personal, para comunicar al presidente del Tribunal o al Ministerio Fiscal "cualquier hecho que revele el estado de insolvencia del deudor" (art. L.631-6).

b) Para decretar el cese parcial de la actividad, o dictar la liquidación judicial de la empresa deudora, el tribunal debe oír o citar al deudor, al administrador, al mandatario judicial, a los interventores " $\mathrm{y}$ a los representantes del comité de empresa o, en su defecto, a los delegados del personal” (art. L.631-15).

c) Si por motivos económicos se hace indispensable, inevitable y urgente proceder al despido de trabajadores durante el período de observación, el administrador debe obtener la autorización previa del Juez Comisario. Antes de solicitarla, sin embargo, deberá consultar con el comité de empresa o, en su defecto, con los delegados del personal en las condiciones previstas en el artículo L.321-9 del Código de Trabajo e informará a la autoridad administrativa competente mencionada en el artículo L.321-8 del mismo Código. En apoyo de su solicitud al Juez Comisario, adjuntará como anexo el dictamen obtenido y los comprobantes de sus gestiones para facilitar la indemnización y la recolocación de los empleados (art. L.631-17).

d) Al igual que en el caso de la salvaguarda, si el plan de saneamiento previera despidos por motivos económicos, "el Tribunal no podrá resolver hasta que haya sido consultado el comité de empresa o, en su defecto, los delegados del personal, en las condiciones previstas en el artículo L.321-9 del Código de Trabajo y hasta que haya sido informada la autoridad administrativa competente mencionada en el artículo L.321-8 del mismo Código”. El plan "precisará sobre todo los despidos que deban producirse en el plazo de un mes desde la resolución". En ese plazo, dichos despidos se producirán por simple notificación del administrador, sin perjuicio de los plazos previstos por la Ley para la comunicación previa y en los convenios o acuerdos laborales colectivos (art. L.631-19).

\subsection{El caso de Portugal 3}

Para concluir esta revisión comparada, resulta de interés mencionar también el sistema portugués, que atiende particularmente a la situación de los trabajadores de la empresa insolvente concursada.

En Portugal hay dos normas de referencia en esta materia. Como punto de partida, el Código do Trabalho, y en particular, el Código da Insolvência e Recuperação de Empresas (CIRE), aprobado por Decreto-Ley No 53/2004, de 18 de Marzo, reformado por el Decreto-Ley No 26/2015, de 6 de Febrero.

Congruente con lo que dispone el art. 347 del Código laboral, el art. 277 del CIRE establece que "Los efectos de la declaración de concurso en el caso de contratos de empleo y las relaciones laborales se regirán exclusivamente por la ley aplicable al contrato de trabajo." Por otra parte, para la ley concursal portuguesa los trabajadores con salarios u otros créditos laborales pendientes son considerados acreedores, a diferencia-nuevamente- de la LC chilena, lo que se traduce en diversas obligaciones y reglas de tutela.

23 Las normas legales citadas han sido traducidas por el autor. 
A) Notificación de la solicitud de declaración de insolvencia al "Comité de Empresa".

En primer término, el art. 26 señala que la petición de declaración de insolvencia deberá ir acompañada de tantos duplicados como sea necesario para su entrega a los 5 mayores acreedores conocidos, al deudor y al Comité de Empresa, que integra entre otros el representante de los trabajadores.

B) Designación judicial de los miembros de la "Comisión de Acreedores" y participación de los trabajadores.

$\mathrm{El}$ art. 66 establece que antes de la primera reunión de la asamblea de acreedores, el juez podrá nombrar una comisión compuesta por tres o cinco miembros y dos suplentes. Uno de los miembros de la comisión, en todo caso, representará a los trabajadores que detenten créditos sobre la empresa, y será elegido por los propios trabajadores o por el comité de empresa, cuando exista.

C) Participación de los trabajadores -acreedores o no- en la Asamblea de Acreedores.

El art. 72.6 señala que "está facultada la participación en la asamblea, hasta tres representantes, del comité de empresa o, en su defecto, hasta tres representantes de los trabajadores designados por ellos mismos, así como el Ministerio Público”. De esta forma, la ley asegura que la opinión de los trabajadores sea oída por la Asamblea de Acreedores, como antecedente a tener en cuenta al momento de tomar las decisiones que puedan afectar la situación de aquellos.

D) Participación de los trabajadores en la confección del "Plan de Insolvencia".

Según el art. 193.3, la asamblea de acreedores puede encargar al administrador concursal la elaboración de un "Plan de Insolvencia", en un plazo razonable, que será preparado "en colaboración con la comisión de acreedores, de existir, con el comité de empresa o representantes de los trabajadores y con el deudor".

El art. 208, por su parte, relativo a la recogida de opiniones sobre el Plan de Insolvencia, establece que "admitida la propuesta de Plan de Insolvencia, el juez fijará un plazo de 10 días para que se pronuncien al respecto el comité de empresa o, en su defecto, los representantes designados por los trabajadores, la comisión de acreedores, de existir, y el deudor o el administrador concursal".

E) Fondo de Garantía Salarial.

Por último, el trabajador también puede recurrir al denominado "Fondo de Garantía Salarial”, que garantiza el pago de los créditos laborales vencidos en los seis meses anteriores a la fecha de inicio del procedimiento de insolvencia.

\section{CONCLUSIONES}

1. La Ley $\mathrm{N}^{\circ} 20.720$ presenta un notorio vacío en materia de reorganización de la empresa deudora, al no considerar de manera clara y explícita la situación de los trabajadores y los créditos laborales ${ }^{24}$.

24 Por la misma razón, con fecha 16 de noviembre de 2016 ingresó a la Cámara de Diputados, en primer trámite constitucional, la moción parlamentaria presentada por el H. Diputado Miguel Ángel Alvarado Ramírez, bajo el rótulo "Modifica la ley $\mathrm{N}^{\circ}$ 20.720, que «Sustituye el régimen concursal vigente por una ley de reorganización y liquidación de empresas y personas, y perfecciona el rol de la Superintendencia del ramo», en 
Esta omisión genera incertidumbre en cuanto a la participación de los créditos laborales en la reorganización -principalmente indemnizaciones por años de servicio-, lo que afecta no solo el interés de los trabajadores sino, también, a la propia empresa que, en un supuesto negativo participación (esto es, que los señalados créditos no son "reorganizables"), puede verse forzada incluso a optar por su propia liquidación, al no poder sobrellevar su carga laboral actual ni las eventuales indemnizaciones que puedan surgir en el contexto de un plan de reorganización.

La situación se hace aún más compleja si se considera que, en materia de reorganización, la normativa actual prescinde del elemento o presupuesto objetivo de todo procedimiento concursal: la insolvencia actual o inminente. Tal circunstancia, por lo mismo, puede derivar en graves abusos del sistema por parte de deudores que, no encontrándose en insolvencia, instrumentalizan el procedimiento de reorganización con fines utilitarios, entre los que bien puede figurar el propósito de eludir sus obligaciones laborales.

2. Las remuneraciones de los trabajadores que continúan prestando servicios tras el inicio del concurso del empleador deben ser consideradas como gastos administrativos o un crédito "de la masa". En el contexto de un proceso concursal, la continuidad de la empresa deudora redunda directamente en beneficio de los acreedores, que podrán pagarse por esta vía, de manera que estos créditos no requieren verificación ni ingresan al concurso.

3. La LC no se ocupa de manera explícita de los trabajadores en el diseño de la propuesta de acuerdo de reorganización. Dicho plan, por ende, debiese contemplar claramente la situación en que quedarán dichos trabajadores y los respectivos contratos de trabajo, precisando en todo caso si la ejecución del referido acuerdo presupone despidos, modificaciones de jornada, traslados, rebaja de sueldos, etc., las que en todo caso deben tener un carácter indispensable, inevitable y urgente, eventualmente justificable ante el juez laboral.

4. Los trabajadores tampoco son oídos en el proceso de toma de decisiones, pese al evidente interés que tienen en sus resultados y efectos. Parece prudente y necesario, por ende, incorporar también un mecanismo que los incluya como tales interesados, al menos en el diseño del plan de reorganización.

el sentido de garantizar el pago de remuneraciones y cotizaciones previsionales de los trabajadores" (Boletín $\mathrm{N}^{\circ}$ 10977-03).

En concreto, la moción plantea tres modificaciones sustanciales a la actual regulación en materia de procedimiento de reorganización: a) Exigir que la empresa deudora se encuentre al día en el pago de las cotizaciones previsionales, como condición para el ejercicio del derecho de opción contemplado en el actual art. $120 \mathrm{~N}^{\circ} 2$, letra c), de la LC; b) Asignarle al veedor el deber de asegurar el pago de las remuneraciones y cotizaciones previsionales; y c) Exigirle a la empresa deudora que se mantenga al día en el pago de las remuneraciones laborales y cotizaciones durante el periodo de protección financiera concursal. La primera de estas tres ideas, sin embargo, fue planteada durante el trámite legislativo de la proyectada Ley $\mathrm{N}^{\circ} 20.720$ y desechada en dos oportunidades: (i) Primero por la Comisión Técnica que conoció inicialmente de la misma, en primer trámite constitucional y a propósito de una indicación en el mismo sentido presentada por el H. Senador Tuma, que incluía además estar al día en el pago de las remuneraciones (véase la indicación 67a a en HisTORIA DE LA LEY N 20.720 (2014), Boletín No 8.324-03, de 26 de julio de 2012, sobre "Indicaciones formuladas durante la discusión en general del proyecto de ley, en primer trámite constitucional”, p. 479); y luego (ii) Por las Comisiones Unidas en segundo trámite constitucional, al estimarse -acertadamente a nuestro entender- que la señalada exigencia "constituiría una barrera de entrada relevante para la reorganización, lo que a la larga afectaría a los propios trabajadores” (Historia DE LA LEY (2014) p. 764). 
5. Como ocurre en las legislaciones extranjeras analizadas, los créditos laborales deben ser considerados como créditos en el concurso, de manera que sus titulares deben intervenir como tales acreedores en el procedimiento de reorganización.

6. Como forma de privilegiar los acuerdos de reorganización de empresas económicamente viables, sin desatender la situación de los trabajadores y de los créditos laborales anteriores al inicio del concurso, los sistemas jurídicos comparados han implementado mecanismos como los fondos estatales de garantía salarial, instituciones de garantía y/o sistemas especiales de seguros de cesantía por insolvencia, con fuentes diferenciadas de aporte y financiamiento; y todo sin perjuicio de la posibilidad de reconocer en estos casos un privilegio para el recupero de esos pagos, en los términos del respectivo acuerdo de reorganización ${ }^{25}$.

\section{BIBLIOGRAFÍA CITADA}

ÁlVAReZ, Manuel (2008): "Suspensiones y reducciones de jornada en el marco de los expedientes de regulación de empleo”, en Rivero, J., Largo, Rita y De Val, Ángel (dir.), La Reestructuración de Empresas (Navarra, Thomson Aranzadi).

López, Carlos (2016): "Régimen aplicable a los créditos laborales en el concurso de acreedores regulado por la Ley 18.387/2008, de 23 de octubre, de Declaración Judicial del Concurso y Reorganización Empresarial", Revista de Derecho del Trabajo, No 10: pp. 171-194.

Martínez, Camilo (2012): Manual de Derecho Concursal (Montevideo, Fundación de Cultura Universitaria, segunda edición).

Mercader, Jesús y Alameda, Ma. Teresa (2015): "Comentario al artículo 64 de la Ley Concursal”, en Comentario de la Ley Concursal. Disponible en: Aranzadi Instituciones, BIB 2015\9058. Fecha de consulta: 14 de diciembre de 2016.

Miller, Alejandro (2008): "Alcance de la venta en bloque de la empresa", en Cuarto Congreso Iberoamericano de Derecho Concursal. Crisis de la Economía Mundial y Concursalidad (Montevideo, Instituto Iberoamericano de Derecho Concursal), pp. 99-103.

Pardo, Pedro L. (2008): "Modificación sustancial de las condiciones de trabajo", en RIVERO J. et al. (dir.), La Reestructuración de Empresas (Navarra, Thomson Aranzadi), pp. $55-100$.

Prendes, Pedro y Muñoz, Alfonso (dir.) (2012): Tratado Judicial de la Insolvencia, Tomo I (Navarra, Aranzadi).

Rivero J. y Largo, Rita (2010): "Delimitación conceptual de la reestructuración de empresas y su incidencia sobre aspectos laborales mercantiles", en RIVERO J. et al. (dir.), La Reestructuración de Empresas (Navarra, Thomson Aranzadi), pp. 17-27.

Rosenbaum, Jorge y Castelo, Alejandro (2010): Aspectos laborales de la Ley de Reforma Concursal y de Reorganización Empresarial, Ley 18.387 (Montevideo, FCU).

SCAlzilli, João Pedro et al. (2016): Recuperação de empresas e falencia (São Paulo, Almedina).

25 Véase OIT, Convenio No 158 , pp. 39 y ss. 
Sierra, Alfredo (2016): "El término del contrato de trabajo a la luz de la nueva ley de reorganización y liquidación de empresas”, en Jequier LEHUEDÉ, Eduardo (edit.), Estudios de Derecho Concursal (Santiago de Chile, Thomson Reuters - La Ley) pp. 229-243.

\section{OTRAS PUBLICACIONES}

Convenio OIT, sobre "Protección de los créditos laborales en Caso de insolvencia DEL EMPLEADOR" (1991). Disponible en:

http://staging.ilo.org/public/libdoc/conventions/Technical_Conventions/Convention_ no._173/173_Spanish/90B09_93_SPAN.pdf Fecha de consulta: 19 de diciembre de 2016.

Guía Legislativa de la CNUDMi, sobre el Régimen de la Insolvencia (2006). Disponible en: https://www.uncitral.org/pdf/spanish/texts/insolven/05-80725_Ebook.pdf Fecha de consulta: 23 de noviembre de 2016.

Historia de la Ley N²0.720 (2014). Disponible en:

https://www.google.cl/search? sourceid=chrome-psyapi $2 \&$ ion $=1 \&$ espv=2\&ie $=$ UTF$8 \& q=$ historia $\% 20$ de $\% 20$ la $\% 20$ ley $\% 2020720 \&$ oq =historia $\% 20$ de $\% 201$ a $\% 20$ ley $\% 20$ \&aqs=chrome.2.69i57j015.5574j0j8 Fecha de consulta: 14 y 15 de noviembre de 2016.

\section{NORMAS CITADAS}

LEY N²0.720 (09/01/ 2014), Reorganización y Liquidación de Empresas y Personas (Chile).

Ley N²0.416 (03/02/ 2010), Estatuto de las Empresas de Menor Tamaño (Chile).

LEY N¹8.387/2008 (23/10/ 2008), Declaración Judicial del Concurso y Reorganización Empresarial (Uruguay).

LEY N 24.522 (20/06/ 1995), Ley de Concursos y Quiebras (Argentina).

LeY N¹1.101 (09/02/ 2005), Regula la recuperación judicial, extrajudicial y quiebra del empresario y la empresa de negocios (Brasil).

Ley No 27.809 (08/08/ 2002), Ley General del Sistema Concursal (Perú).

LEY N 1.116 (27/12/ 2007), Régimen de Insolvencia Empresarial en la República de Colombia y se dictan otras disposiciones (Colombia).

LEY N ${ }^{\circ} 22 / 2003$ (09/07/ 2003), Ley Concursal (España).

Real Decreto Legislativo 2/2015 (23/10/ 2015), Ley del Estatuto de los Trabajadores (España).

Real Decreto 505/1985 (06/03/ 1985), Organización y Funcionamiento del Fondo de Garantía Salarial (España).

CODE DE COMMERCE (Francia).

Decreto-Ley No 53/2004 (18/03/ 2004), Código da Insolvência e Recuperação de Empresas (Portugal).

Directiva 2008/94/CE del Parlamento Europeo y del Consejo (22/10/2008), sobre Protección de los trabajadores asalariados en caso de insolvencia del empresario. 
JeQuiER LeHUEDÉ, Eduardo Créditos laborales y trabajadores en el procedimiento de reorganización...

\section{JURISPRUDENCIA CITADA}

Sentencia TJRS de Brasil, 6a Cámara Civil (27 de agosto de 2015), AI 70065432858, Rel. Des. Elisa Carpim Corrêa, j.

Sentencia TJSP de Brasil, Cámara Reservada de Falencia y Recuperación (29 de marzo de 2011), AI 0060505-11.2010.8.26.0000, Rel. Des. Lino Machado.

Sentencia TJRJ de Brasil, 4a Cámara Civil (20 de julio de 2010), AI 002073773.2010.8.19.0000, Rel. Des. Mário dos Santos Paulo, j. 